\title{
Design and test of 4ZZ-4A2 full-hydraulic self-propelled jujube harvester
}

\author{
Wei Fu' ${ }^{1,2}$, Zhiyuan Zhang ${ }^{1,2}$, Kai Ding ${ }^{1,2}$, Weibin Cao ${ }^{1,2}$, Za Kan $^{1,2^{*}}$, Junbing Pan ${ }^{1,2}$, Yudong Liu ${ }^{1,2}$ \\ (1. College of Mechanical and Electrical Engineering, Shihezi University, Shihezi 832003, Xinjiang, China; \\ 2. Agricultural Machinery Key Laboratory of Xinjiang Production and Construction Corps, Shihezi 832003, Xinjiang, China)
}

\begin{abstract}
The cultivated area of jujube in Xinjiang has increased rapidly in recent years. While the jujube harvest by hand has the shortage of high labor intensity, low efficiency and high labor cost, in addition, the harvesting machinery applying to dwarf and dense planting mode of jujubes is unavailable in Xinjiang. The 4ZZ-4A2 based on the full-hydraulic self-propelled jujube harvester was designed to solve the above problems. The harvester was mainly composed of a frame, a vibrating device, a jujube collecting and conveying device, an air separation device, a steering system, a hydraulic system and a jujube suction device and was capable of completing vibration, collection, conveying, cleaning and sundries removal work of jujubes through one step. The jujubes dropped on the ground were picked up at the same time. The AMESim simulation software was adopted to perform simulation analysis on the overall hydraulic system. The results showed that the speed of the vibrating motor was stable at about $650 \mathrm{r} / \mathrm{min}$ (the corresponding vibration frequency is $10.83 \mathrm{~Hz}$ ) with the torque of $80 \mathrm{~N} \cdot \mathrm{m}$, the speed of the conveyor motor was stable at $77 \mathrm{r} / \mathrm{min}$ with the torque of $77 \mathrm{~N} \cdot \mathrm{m}$; the speed of the fan motor was stable at $54 \mathrm{r} / \mathrm{min}$ with the torque of $53.6 \mathrm{~N} \cdot \mathrm{m}$; the speed of the walking motor fluctuated around $100 \mathrm{r} / \mathrm{min}$ with the torque of about $1000 \mathrm{~N} \cdot \mathrm{m}$; the hydraulic steering system responded rapidly and could satisfy the actual working requirements of the jujube harvester. The jujube garden test results showed that the harvester could reach to the optimum harvesting effect when running at the speed of $0.5 \mathrm{~m} / \mathrm{s}$. Under such speed, the ground jujube picking rate was $45.1 \%$, the tree jujube harvesting rate was $93.2 \%$, the loss rate was $2.9 \%$, and the damage rate was $0.9 \%$. This study can provide theoretical basis and technical support for the jujube harvester.
\end{abstract}

Keywords: harvester, jujube, hydraulic simulation, dwarf and close planting, design DOI: $10.25165 /$ j.ijabe.20181104.3981

Citation: Fu W, Zhang Z Y, Ding K, Cao W B, Kan Z, Pan J B, et al. Design and test of 4ZZ-4A2 full-hydraulic self-propelled jujube harvester. Int J Agric \& Biol Eng, 2018; 11(4): 104-110.

\section{Introduction}

Xinjiang is very suitable for planting jujubes with superior quality by virtue of unique geographical location and climate conditions. According to statistics, the jujube planting area in Xinjiang has been more than 0.52 million $\mathrm{hm}^{2}$ by the end of 2015, ranking first in China. With adjustment of agricultural planting structure, the jujube planting area is still increasing in Xinjiang ${ }^{[1]}$. At present, the jujube harvesting mainly depends on manual pick, which is high in labor intensity, low in efficiency and high in cost. Therefore, mechanical harvesting is badly needed to improve operation efficiency and reduce labor cost.

Since 1960s, relevant studies of fruit harvesting had been developed overseas. Whitney et al. ${ }^{[2]}$ performed a test on Valencia oranges receiving fruit drop agent in 5 harvest seasons by adopting the pneumatic vibrating harvester. The research showed that the method was low in efficiency, and the yield of the orange

\section{Received date: $2017-03-20 \quad$ Accepted date: $2018-04-26$}

Biographies: Wei Fu, PhD, Associate Professor, research interests: fruit and vegetable harvesting machinery. Email: fuwei001@126.com; Zhiyuan Zhang, Master, research interests: mechanical design and theory. Email: 18394180126@ 163.com; Kai Ding, Master, research interests: fruit harvesting machinery, Email: dk_shz@163.com; Weibin Cao, PhD, Professor, research interests: field machinery, Email: wbc828@163.com; Junbing Pan, Master, research interests: fruit harvesting machinery, Email: pjbdzq@163.com; Yudong Liu, Master, research interests: fruit harvesting machinery, Email: 18353232219@163.com.

*Corresponding Author: Za Kan, Professor, research interests: agriculture and animal husbandry machinery and equipment. Mailing address: College of Mechanical and Electrical Engineering, Shihezi University, Shihezi 832003, China. Tel: +86-13031321373, Email: kz-shz@163.com. was reduced by $16 \%$ compared with that of manual picking. Whitney et al. ${ }^{[3]}$ performed a test on oranges receiving fruit drop agent in 5 harvesting seasons by using FMC-4000 embrace-shaking type vibrating harvester, with the vibrating time of 3-7 s and the yield rate of more than $90 \%$. The research showed that the yield of the orange was reduced by $10 \%$ compared with that of manual picking. Hutton et al. ${ }^{[4]}$ conducted a 3 years study into the effect of abscission chemicals on the productivity of an experimental air shaker harvesting oranges. The research showed that air shaker system achieved a fruit recovery rate in excess of $80 \%$ when the fruit bonding strength was less than $19.6 \mathrm{~N}$ and it had a potential harvest rate of $20 \mathrm{t} / \mathrm{h}$. Hedden et al. ${ }^{[5]}$ performed a test on Hamlin and Valencia oranges for 5 harvesting periods by utilizing four different embrace-shaking type test samples and spraying fruit drop agent during harvesting with the vibrating time of each tree as $7 \mathrm{~s}$. The yield rate was increased from $64 \%$ to $90 \%$. Blanco-Roldán et al. ${ }^{[6]}$ classified olive into four grades by maturity (MFI) when performing vibrating harvesting on the olive. The vibrating time was $20 \mathrm{~s}$, and the harvesting efficiency was over $90 \%$. Coppock performed a test on oranges without fruit drop agent for 3 harvesting seasons by adopting the branch vibrating type harvester with the vibrating time of $56 \mathrm{~s}$. The drop rate of mature oranges was $76 \%{ }^{[7]}$. Coppock et al. ${ }^{[8]}$ performed harvesting tests by using three kinds of branch vibrating type harvester, all leading to yield reduction. Mann et al. ${ }^{[9]}$ performed a harvesting test on sea buckthorn and obtained a conclusion that the harvesting effect was best at the frequency of $25 \mathrm{~Hz}$ and the amplitude of $32 \mathrm{~mm}$. Peterson developed a vibrating harvesting device with a rod drum, which was arranged on two sides of the crown. A crown vibrating pull-type fruit harvester was also developed to perform harvesting 
tests on blueberry, blackberry and orange $e^{[10,11]}$. So et al. ${ }^{[12,13]}$ studied a full-hydraulic self-propelled harvester adopting an aluminum vibrating rod inserted into the upper portion of the crown to achieve reciprocating vibration and complete harvesting of mature raspberry. In 2003, Lee et al. ${ }^{[14]}$ from Chungnam National University developed relevant studies on jujube harvesting and developed a full-hydraulic self-propelled jujube harvester mainly used in sparse jujube gardens with large row spacing.

In recent years, China has also developed relevant studies on jujube harvesting machinery. Xinjiang Academy of Agricultural and Reclamation Science developed a 4YS-24 jujube harvester which was matched with $29.5 \mathrm{~kW}$ tractor to vibrate jujubes from the branch by means of inertia force generated by the vibrating device in the trunk embracing and shaking mode; it was applicable to the jujube trees with the trunk diameter of $80-200 \mathrm{~mm}$ and capable of achieving the net rate of $91.4 \%$, but it could not perform continuous harvesting and was only applicable to sparse jujube gardens with large row spacing ${ }^{[15]}$. Tarim University developed an air suction jujube harvester with high working efficiency, but the harvested jujubes were high in impurity rate, and it could only be used for collecting jujubes dropping on the ground ${ }^{[16]}$.

As the dwarf and close planting mode is adopted for jujubes in Xinjiang, the tree height is controlled below $2.25 \mathrm{~m}$, and its planting area covers more than $90 \%$ of the total area of the jujube garden. In the above studies, the jujubes in dwarf and close planting mode in Xinjiang were not adapted to mechanized harvesting. Therefore, this article designs a full-hydraulic self-propelled jujube harvester which can complete harvesting of jujubes on trees and picking of jujubes on the ground to solve the mechanical harvesting problem of jujubes in Xinjiang.

\section{Overall structure and harvesting principle of the harvester}

\subsection{Overall structure}

The 4ZZ-4A2 self-propelled jujube harvester is mainly composed of a frame, a vibrating device, a jujube collecting and conveying device, an air separation device, a steering system, a hydraulic system, a jujube suction device, etc. The harvester is mainly used for harvesting jujubes in the dwarf and close planting mode and capable of completing vibration, collection, conveying, cleaning selection, sundries removal and jujube collection of jujubes through one step and also picking the jujubes dropping on the ground. The harvester adopts a self-propelled walking device, with the rear wheels achieving a steering function. The overall structure is illustrated in Figure 1 and the main technical parameters listed in Table 1.

Table 1 Structure parameters of self-propelled jujube harvester

\begin{tabular}{lc}
\multicolumn{1}{c}{ Parameters } & Values \\
\hline Structure form & Self-propelled \\
Frame height adjustment mode & Hydraulic \\
Overall dimension $(\mathrm{L} \times \mathrm{W} \times \mathrm{H}) / \mathrm{mm}$ & $5300 \times 2600 \times 3300$ \\
Engine rated power $/ \mathrm{kW}$ & 74 \\
Engine rated $\mathrm{speed} / \mathrm{r} \cdot \mathrm{min}^{-1}$ & 2200 \\
Work speed $/ \mathrm{km} \cdot \mathrm{h}^{-1}$ & $1-3$ \\
Overall mass $/ \mathrm{kg}$ & 3650 \\
Row spacing $/ \mathrm{mm}$ & 2000 \\
Wheel-tread $/ \mathrm{mm}$ & 3370 \\
Minimum $\mathrm{ground}$ clearance $/ \mathrm{mm}$ & 350 \\
\hline
\end{tabular}

\subsection{Working principle}

The overall ground height is adjusted by adjusting four hydraulic cylinders connecting the frame to adapt to harvesting of jujube trees in different heights. During operating, the jujube harvester straddles on the jujube tree, harvesting 1 row of trees each time. With advancing of the harvester, the vibrating device 7 generates continuous reciprocating vibrating force to drive the jujube trees to vibrate, generate inertia force by means of transfer of the branch force and further overcome the jujube-stem connection force; the jujubes fall onto the inclined jujube collecting device 13 under the force and then roll onto the horizontal conveying device 1 to be conveyed to the lifting device 12 behind the body; the lifting device lifts the jujubes into the jujube collection box 10; in the conveying process of the lifting device, the air separation device 14 will remove sundries in the jujubes which fall into the jujube box finally, and the harvesting of the jujubes on the tree is finished; meanwhile, 2 negative pressure air pipes 2 are arranged in front of the harvester and used for performing pneumatic picking operation of the jujubes under the effect of the fan 3 .

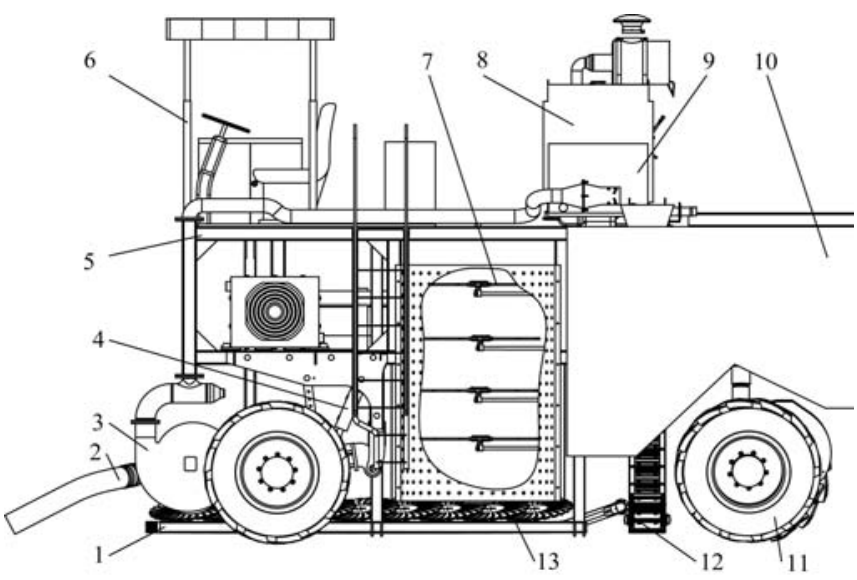

a. Front view

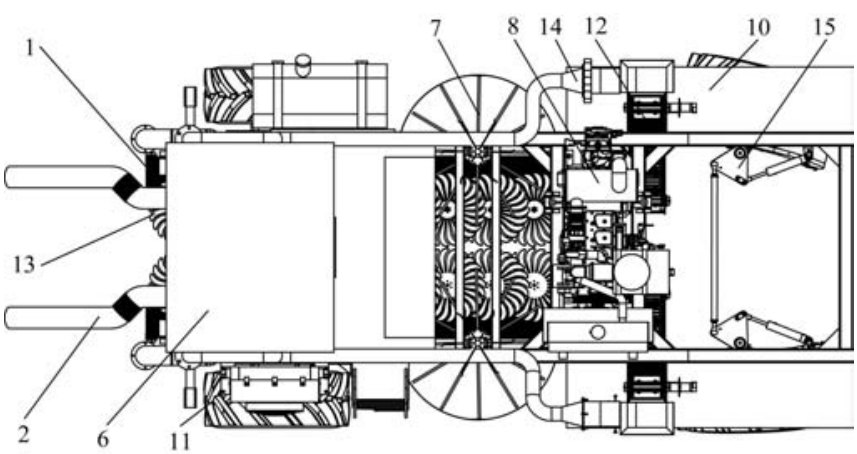

\section{b. Top view}

1. Conveying device 2. Negative pressure air pipe 3. Fan 4. Body lifting oil cylinder 5. Frame 6. Cab 7. Vibrating device 8. Engine 9. Oil tank 10. Jujube collection box 11. Walking wheel 12. Lifting device 13. Inclined jujube collecting device 14. Air separation device 15. Steering system

Figure 1 Structure diagram of self-propelled jujube harvester

\section{Design of critical components}

\subsection{Vibrating device}

3.1.1 Structure design of vibrating device

The vibrating device is the core component of the jujube harvester, composed of a slider-crank mechanism and an end vibrating mechanism fixed on two sides of the middle of the jujube harvester vertically and symmetrically, as shown in Figure 2. The power of the slider-crank mechanism is provided hydraulically. 
In the working process, the slider-crank mechanism drives the end vibrating mechanism to reciprocate, and the end vibrating mechanism transfers the acting force to jujubes which generate large inertia force and fall off the tree by overcoming the connection force of the stem and branches.

The end vibrating mechanism is a mechanical component in direct contact with the jujube tree branches and composed of rods and a rod disk. 12 rods are evenly distributed on the circumference of the rod disk. To reduce damage to the jujube tree branches, the rod disk adopts movable hinge joint; the rods are $530 \mathrm{~mm}$ in length and $15 \mathrm{~mm}$ in diameter; the vibration frequency is $10-15 \mathrm{~Hz}$, and the amplitude is $6-9 \mathrm{~mm}$.

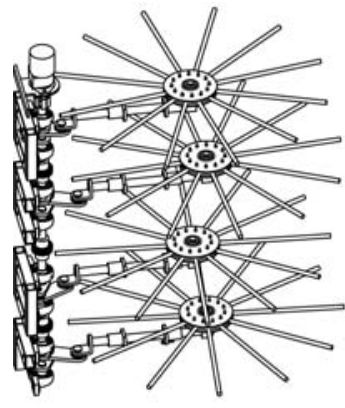

a. Vibrating device

1. Connecting seat 2. Crank 3. Connecting rod 4. Push rod 6. Rod disk

Figure 2 Structure diagram of vibrating device

\subsubsection{Dynamic calculation of vibrating device}

To simplify calculation, a vibrating model is built with two assumptions: the vibrating mechanism rotates at even speed in a servo motor in the working process; the jujube tree branches are in linear vibration. The force transfer process can be seen as conversion of crank output force into branch vibrating force and vibrating mechanism vibrating force. The vibrating model is illustrated in Figure 3.

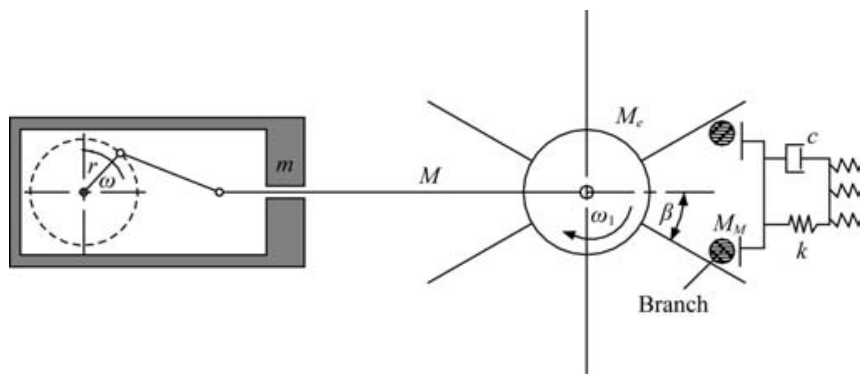

Figure 3 Vibrating model

$M$ is adopted to show the mass of the crank mechanism, $\mathrm{kg}$; $M_{M}$ means the mass reduced from the branches (mainly the mass of the dropping jujubes), $\mathrm{kg} ; M_{e}$ is the mass of the vibrating component, $\mathrm{kg} ; m$ is the unbalance mass in the mechanism, $\mathrm{kg} ; M_{t}$ is the model total mass, $\mathrm{kg}$, and $M_{t}=M+M_{M}+m ; A$ is the branch horizontal position amplitude, $\mathrm{mm} ; \varphi$ is the phase angle, rad.

Simultaneous displacement of the branches can be expressed as

$$
x_{M}=A \sin (\omega t-\varphi)
$$

The branch horizontal position amplitude in Equation (1) can be calculated according to [4]:

$$
A=\frac{m r \omega^{2}}{\sqrt{\left(k-M_{t} \omega^{2}\right)^{2}+(c \omega)^{2}}}
$$

Phase angle $\varphi$ is

$$
\tan \varphi=\frac{k \omega c}{1-M_{t} k \omega^{2}}
$$

Calculated as per Zoltán Láng ${ }^{[17]}$, the effective work is:

$$
\begin{aligned}
W_{S} & =\int_{0}^{T=2 \pi / \omega} \frac{A^{2} \omega}{2}\left[k-\left(M+M_{M}+M_{e}\right) \omega^{2}\right] \\
\sin & {[2(\omega t-\varphi)] d t+\int_{0}^{T=2 \pi / \omega} A^{2} c \omega^{2} \cos ^{2}(\omega t-\varphi) d t } \\
& =A^{2} c \omega \pi
\end{aligned}
$$

The average power driving the slider-crank mechanism is:

$$
P_{a v}=\frac{W_{S}}{T}=\frac{1}{2} \frac{\left(m r \omega^{2}\right)^{2} k \omega^{2}}{\left(k-M_{t} \omega^{2}\right)^{2}+(c \omega)^{2}}
$$

The power of the hydraulic motor driving the single slider-crank mechanism is

$$
P_{t}=P_{a v}=\frac{1}{2} \frac{\left(m r \omega^{2}\right)^{2} k \omega^{2}}{\left(k-M_{t} \omega^{2}\right)^{2}+(c \omega)^{2}}
$$

In Equation (6), in case $k=1, c=0, r=12 \mathrm{~mm}, m=0.86 \mathrm{~kg}$, $M=6.73 \mathrm{~kg}, M_{e}=6.86 \mathrm{~kg}$ and $M_{M}=0.5 \mathrm{~kg}, P_{t}=0.094 \mathrm{~kW}$; the vibration generator on each side is composed of 6 mechanisms and driven by 1 motor, the motor power is $P$, and $P=6 \cdot P_{t}=0.564 \mathrm{~kW}$.

\subsection{Jujube collecting and conveying device}

The jujube collecting and conveying device is composed of the inclined jujube collecting device, the horizontal conveying device and the lifting device, as shown in Figure 4. It is used for collecting and conveying the dropping jujubes to the jujube collection box. The inclined jujube collecting device is composed of 2 groups of inclined disks arranged symmetrically. Each group is provided with 9 inclined disks. The horizontal conveying device is arranged symmetrically, fixedly installed under the inclined disks horizontally and driven by the hydraulic motor. The lifting device is arranged behind the harvester and on 2 sides of it symmetrically. It is driven by the hydraulic motor to convey the jujubes to the jujube collection box. The horizontal conveying device and the lifting device both adopt chain conveying. The grid is installed on the chain, the grid clearance is far smaller than the jujube diameter, meanwhile the baffle is installed on the side of the grid to prevent dropping of the jujubes; the lifting device is provided with a horizontal baffle which is used for lifting the jujubes and conveying them to the jujube collection box.

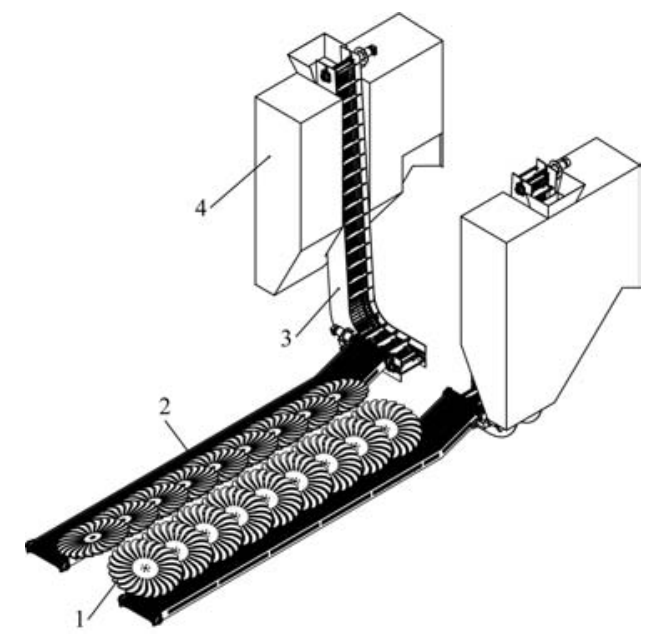

1. Inclined disc 2. Horizontal conveying device 3. Lifting device 4. Jujube collection box

Figure 4 Jujube collecting and conveying device

The inclined jujube collecting device is composed of two rows of inclined disks installed symmetrically. The inclined disks are 
arranged with the part close to the middle end high and the part close to the horizontal conveying device low. The dropped jujubes can roll from the inclined disks to the horizontal conveying device conveniently, as shown in Figure 4.

According to measurement in test, the long axis diameter of gray jujubes: $19.62-32.59 \mathrm{~mm}$, and the short axis diameter of gray jujubes: 10.78-23.66 $\mathrm{mm}$; the long axis diameter of jun-jujubes: 41.46-49.99 mm, and the short axis diameter of jun-jujubes: 25.69-38.79 $\mathrm{mm}$; the trunk diameter: $65-105 \mathrm{~mm}$. To ensure that the jujube tree can pass from the middle of the inclined disks and the jujubes can roll to the horizontal conveying device, the inclined disk diameter $D=550 \mathrm{~mm}$, the disk installation angle $\theta=0.3141$, the clearance $d=8 \mathrm{~mm}$, the installation spacing $l=75 \mathrm{~mm}$, as shown in Figure 5.

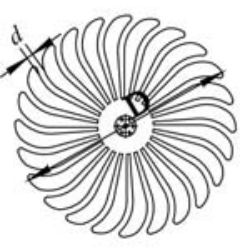

a. Inclined disk

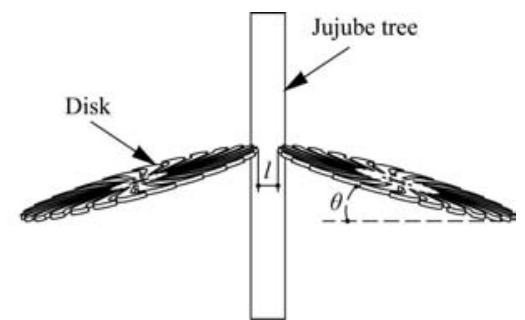

b. Jujube tree passing the disks
Note: $l$ is the installation spacing between two disks, mm; $\theta$ is the disk angle, rad.

Figure 5 Passing capability diagram

\subsection{Picking conveying-cleaning device}

The picking-conveying-cleaning device can complete picking and conveying of jujubes dropping onto the ground as well as cleaning of the jujubes conveyed by the lifting device, as shown in Figure 6. As the dropping jujubes account for $30 \%-50 \%$ of the total output during the harvesting seasons in Xinjiang, the jujubes on the ground should be picked first.

During work, the hydraulic system drives the fan to rotate and form negative pressure at the jujube suction port to suck the jujubes from the port and convey them to the jujube collection box through the air pipes. Meanwhile, the jujubes conveyed by the lifting device fall into the jujube collection box with the sundries removed by the air around the jujube outlet. To ensure that the conveying pipeline is smooth and capable of meeting the requirements for air force required by cleaning, the pipeline inner diameter is $150 \mathrm{~mm}$, and the fan power is $2 \mathrm{~kW}$.

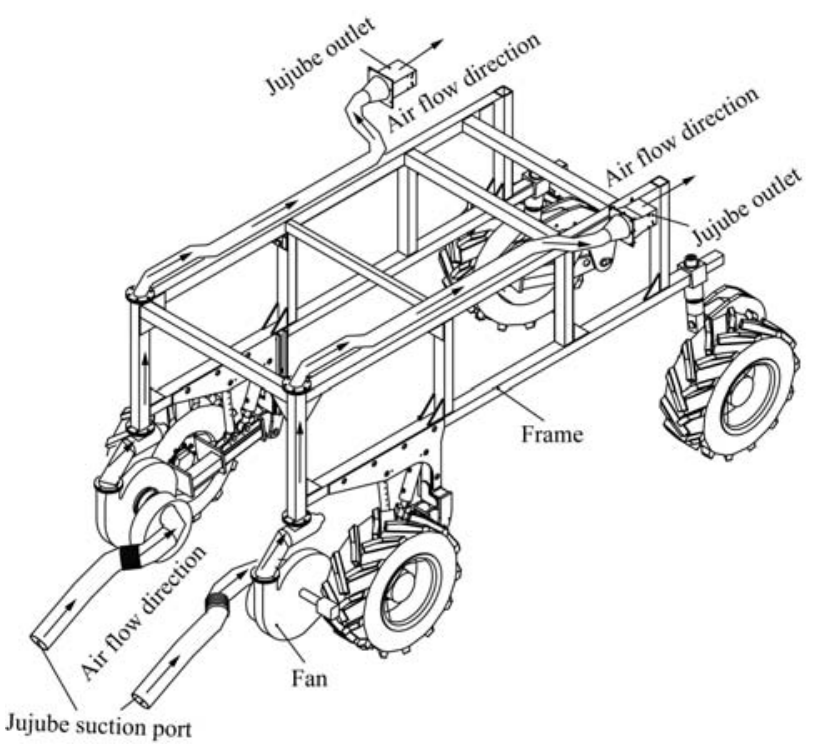

Figure 6 Picking conveying-cleaning device

\subsection{Type selection design and simulation of hydraulic system} 3.4.1 Type selection design of hydraulic system

To acquire stable reliable power, the $4 \mathrm{ZZ}-4 \mathrm{~A} 2$ self-propelled jujube harvester adopts the full-hydraulic driving mode. The overall hydraulic system is composed of the vibrating system, the conveying and cleaning system (including the fan system, the horizontal conveying system and the lifting system), the steering system and the walking system (Figure 7).

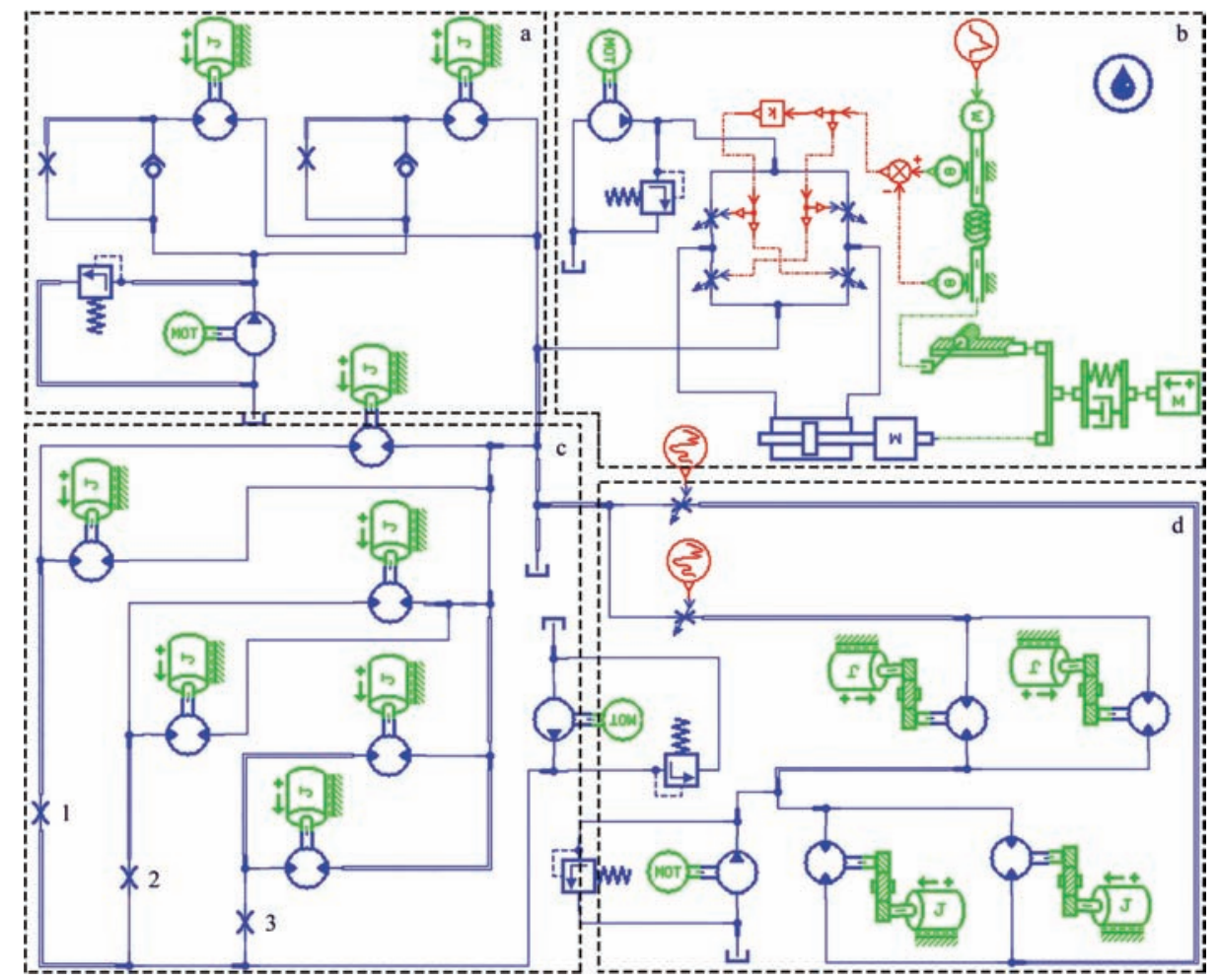

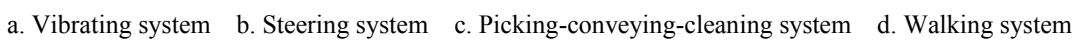
Figure 7 Hydraulic simulation 


\subsubsection{Simulation of hydraulic system}

In order to analyze working parameters of the hydraulic system in the operating state, the article adopts AMESim (from French IMAGINE company) hydraulic simulation software to build a simulation model ${ }^{[18-21]}$, as shown in Figure 7 . The whole simulation model is divided into four hydraulic subsystems: the vibrating system $a$, the steering system $b$, the picking-conveyingcleaning system $\mathrm{c}$ and the walking system $\mathrm{d}$. The vibrating system is provided with 2 hydraulic motors, achieving proportional speed regulation manually; the steering system mainly controls the hydraulic oil cylinder to stretch and drive the steering pull rod to achieve steering; the picking-conveying-cleaning system is provided with 6 hydraulic motors, achieving motor speed regulation manually; the walking system requires 4 hydraulic motors in total to provide power for the wheels respectively. In the whole simulation model, the motor needs to build a connection relation with the load. Estimation of the torque of the walking motor is shown as the Equation (7):

$$
T=\mu G R=9550 \frac{P}{n}=3723(\mathrm{~N} \cdot \mathrm{m})
$$

where, $T$ is the tire total torque, $\mathrm{N} \cdot \mathrm{m} ; \mu$ is the tire rolling resistance coefficient; $G$ is the overall weight, $\mathrm{N} ; R$ is the tire radius, $\mathrm{m} ; P$ is the power, $\mathrm{kW} ; n$ is the speed, $\mathrm{r} / \mathrm{min}$. The jujube harvester has the overall weight of $3650 \mathrm{~kg}$, operating in the sandy soil (the sandy soil tire rolling resistance coefficient is 0.2 ), the operating speed is $3.6 \mathrm{~km} / \mathrm{h}$, and the tire diameter is $1.2 \mathrm{~m}$. Each tire torque is:

$$
T_{1}=T / 4=930.75(\mathrm{~N} \cdot \mathrm{m})
$$

After modeling, the parameters of the components are set, the torque of the walking motor is $1000 \mathrm{~N} \cdot \mathrm{m}$, and the torque of other motors is set to be $20 \mathrm{~N} \cdot \mathrm{m}$. The components and parameters of the hydraulic system listed in Table 2 . The system simulation operation time is $5 \mathrm{~s}$ at the interval of $0.03 \mathrm{~s}$. The simulation results are Figures 8-11.

\begin{tabular}{|c|c|c|}
\hline Component & Model & Parameters \\
\hline Vibrating motor & BMP-36-2AMB & Speed $1050 \mathrm{r} / \mathrm{min}$; Displacement $36 \mathrm{cc} / \mathrm{rev}$ \\
\hline Horizontal conveyor motor & BMP-36-2AMB & Speed $1050 \mathrm{r} / \mathrm{min}$; Displacement $36 \mathrm{cc} / \mathrm{rev}$ \\
\hline Lifting motor & BMP-36-2AMB & Speed $1050 \mathrm{r} / \mathrm{min}$; Displacement $36 \mathrm{cc} / \mathrm{rev}$ \\
\hline Fan motor & M097-8 (1241071236) & Speed $1000 \mathrm{r} / \mathrm{min}$; Displacement $25 \mathrm{cc} / \mathrm{rev}$ \\
\hline Walking motor & IGY5000T2-B19-35/17.5 & Speed $1500 \mathrm{r} / \mathrm{min}$; Displacement $25 \mathrm{cc} / \mathrm{rev}$ \\
\hline Conveying cleaning pump & A10V028DFR1/31L-PSA12N00 & Speed $1800 \mathrm{r} / \mathrm{min}$, displacement $25 \mathrm{cc} / \mathrm{rev}$; limit of $11 \mathrm{MPa}$ \\
\hline Vibrating pump & P124-G25182ID 85G (rotate left) & Speed $1800 \mathrm{r} / \mathrm{min}$, displacement $25 \mathrm{cc} / \mathrm{rev}$; limit of $11 \mathrm{MPa}$ \\
\hline Walking pump & 90L075KA1NN80P3S1F03GBA353524 & Speed $1500 \mathrm{r} / \mathrm{min}$, displacement $75 \mathrm{cc} / \mathrm{rev}$; limit of $35 \mathrm{MPa}$ \\
\hline Steering pump & GelanrexA10VS045 & Speed $1500 \mathrm{r} / \mathrm{min}$, displacement; $45 \mathrm{cc} / \mathrm{rev}$; limit of $10 \mathrm{MPa}$ \\
\hline Hydraulic cylinder & HSGF01-80-45B300 & Diameter $45 \mathrm{~mm}$, length $33 \mathrm{~cm}$ \\
\hline
\end{tabular}

Table 2 Hydraulic system components

\subsubsection{Simulation result analysis}

Figure 8 shows the speed of the motor components. After $0.3 \mathrm{~s}$, the motor speed enters the stable state, the speed of the vibrating motor is stable at about $650 \mathrm{r} / \mathrm{min}$ (corresponding vibration frequency of $10.83 \mathrm{~Hz}$ ), the speed of the conveyor motor is stable at $77 \mathrm{r} / \mathrm{min}$, the speed of the fan motor is stable at $54 \mathrm{r} / \mathrm{min}$, and the speed of the walking motor fluctuates around $100 \mathrm{r} / \mathrm{min}$. Under the effect of external load and the electric control throttle valve, the walking motor has certain fluctuation in speed; the other motors need to keep stable speed during operating, which can be achieved by manually adjusting the throttle valve.

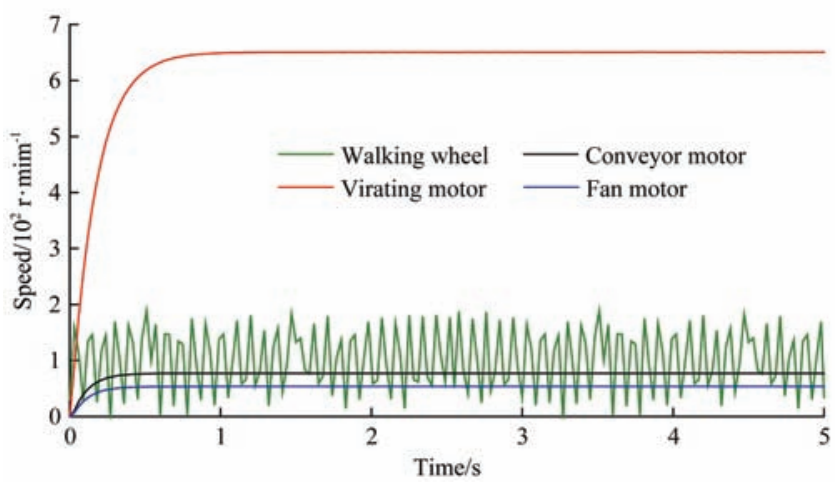

Figure 8 Diagram of hydraulic system motor speed

The torque of the motors is shown in Figure 9. Figure 9a is the torque of walking wheels, and Figure $9 \mathrm{~b}$ is the torque of the fan motor, the vibrating motor and the conveyor motor. Due to the fact that the load connected by the motor has certain mass and inertia force, the torque is increased gradually within $0-0.3 \mathrm{~s}$ and changes with the curve law after $0.3 \mathrm{~s}$, the torque of the fan motor is $53.6 \mathrm{~N} \cdot \mathrm{m}$, the torque of the vibrating motor is $80 \mathrm{~N} \cdot \mathrm{m}$, the torque of the conveyor motor is $77 \mathrm{~N} \cdot \mathrm{m}$, and the torque of the walking wheels is $1000 \mathrm{~N} \cdot \mathrm{m}$, so the motors are stable in operation. As the load of the walking motor has great change, the motor curve has large fluctuation. Meanwhile, all the motor output torque is larger than the theoretically calculated torque, showing that the hydraulic system is reasonable in design.

Figure 10 shows the subsystem flow diagrams. $a$ is the vibrating system flow diagram, the flow of 2 motors is both $23 \mathrm{~L} / \mathrm{min}$, the relief valve is a system protection component, its flow changing with the system; the throttle valve is a hydraulic pump flow adjusting component, the manual signal input mode is adopted to simulate throttling port openness change, a fixed value is set in each simulation, and the throttling port diameter is set to be $0.5 \mathrm{~mm}$ in this simulation. $\mathrm{b}$ is the conveying and cleaning system flow diagram. The system hydraulic pump is a one-way quantifying pump with the flow of $42 \mathrm{~L} / \mathrm{min}$. The relief valve has the flow of $28 \mathrm{~L} / \mathrm{min}$, the throttle valves 1,3 have the flow (flow sum of conveyor motors) of $5.6 \mathrm{~L} / \mathrm{min}$, and the throttle valve 2 has the flow (flow sum of fan motors) of $2.7 \mathrm{~L} / \mathrm{min} . \quad \mathrm{c}$ is the walking system flow diagram. The system hydraulic pump is a one-way quantifying pump with the flow of $112.5 \mathrm{~L} / \mathrm{min}$, the flow of the relief valve fluctuates with the system flow, and the flow of the 4 walking motors fluctuates stably around $15-30 \mathrm{~L} / \mathrm{min}$. The results show that the hydraulic system of the harvester is small in impact and reasonable in design. In the subsystems, the flow of the pumps is the flow sum of the components. 


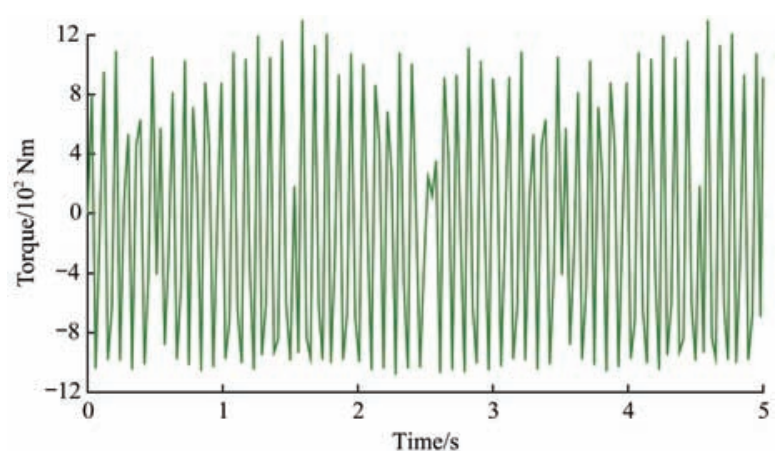

a. Torque of walking wheels

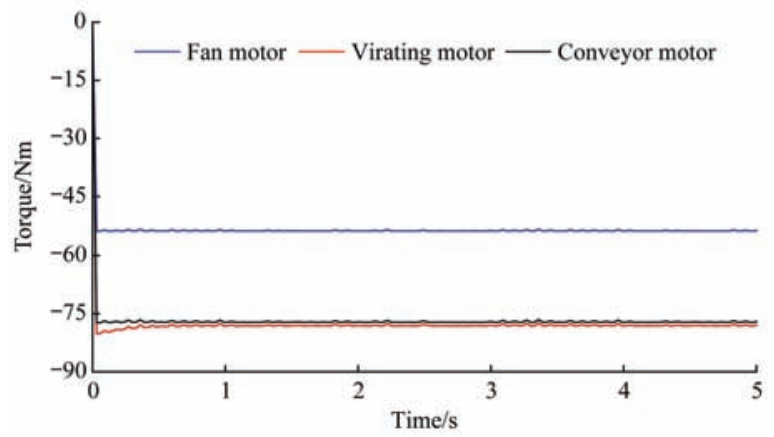

b. Torque of fan motor, vibrating motor and conveyor motor

Figure 9 Torque of the motors

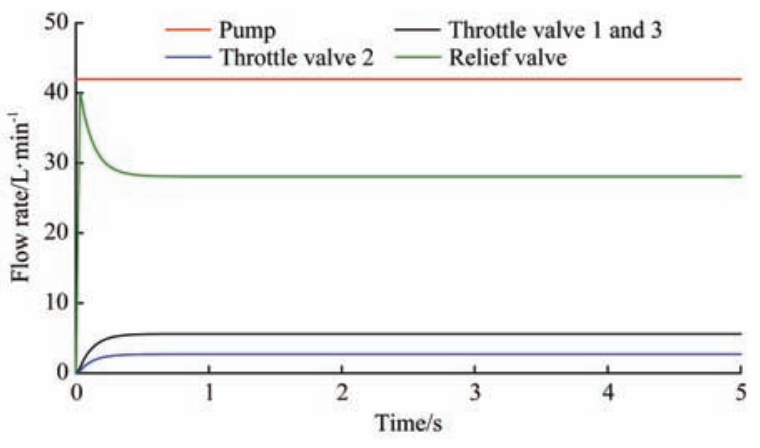

a. Flow of vibration system

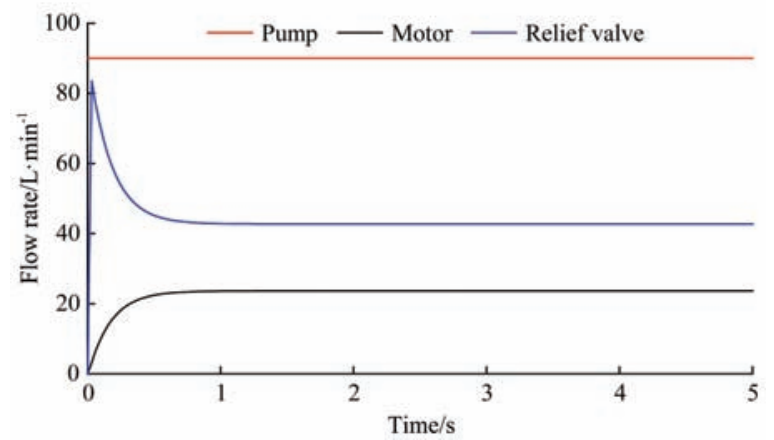

b. Flow of conveying and cleaning system

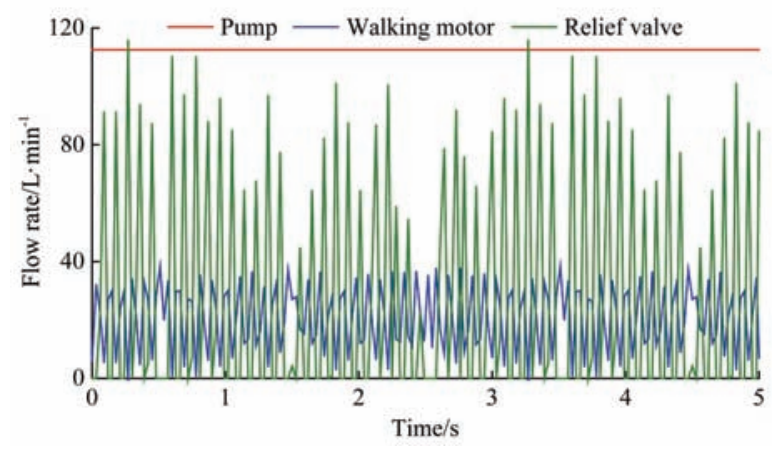

c. Flow of walking system

Figure 10 Subsystem flow diagrams
Figure 11 shows load a, displacement $\mathrm{b}$ and speed $\mathrm{c}$ of the steering cylinder. In Figure a, at 1-1.6 s, the oil cylinder load is increased in maximum and becomes stable after $1.6 \mathrm{~s}$; the stable value is $2000 \mathrm{~N}$. Meanwhile, Figure b shows that the speed tends to be stable after $1.6 \mathrm{~s}$, at the moment, the oil cylinder displacement begins to change and reaches the maximum stroke at $4 \mathrm{~s}$, which is 0.035. Figure $\mathrm{c}$ shows that the oil cylinder moving speed is increased rapidly at $1.6-2 \mathrm{~s}$ with the maximum of $0.014 \mathrm{~m} / \mathrm{s}$; the oil cylinder moves at the maximum speed evenly after $2 \mathrm{~s}$, and the speed is reduced to 0 after $4 \mathrm{~s}$.

According to Figure 11, the oil cylinder makes a response rapidly after the load of the steering oil cylinder reaches the maximum and moves at the speed of $0.014 \mathrm{~m} / \mathrm{s}$. The oil cylinder reaches the maximum displacement after $2 \mathrm{~s}$. In the figure, the curve change is stable, and the steering time is short, complying with the requirements for the steering system.
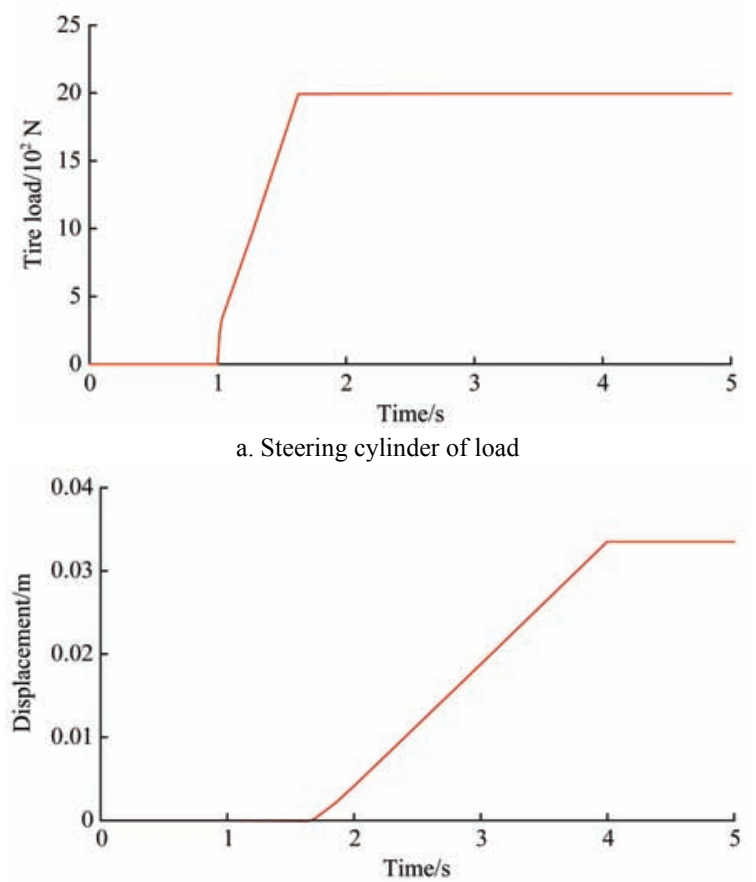

b. Steering cylinder of displacement

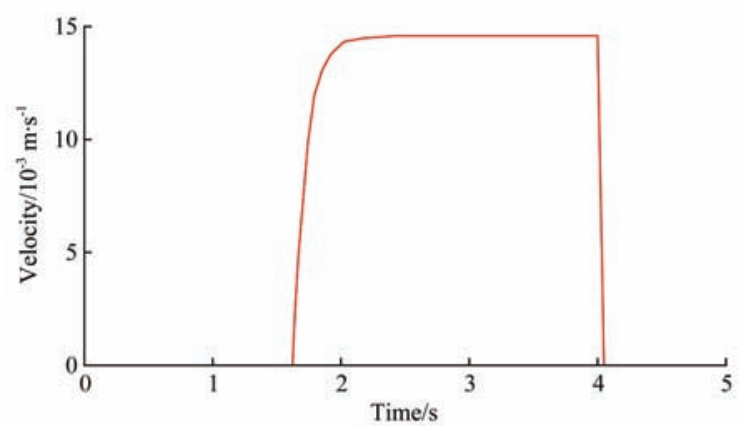

c. Steering cylinder of speed

Figure 11 Steering oil cylinder

The simulation results show that the speed and torque of the rotating components in the hydraulic system tend to be stable with time going during normal operation; the subsystem flow and motor component flow are basically stable under the effects of the relief valves and the throttle valves; the hydraulic component type selection is reasonable and capable of meeting the actual operating requirements of the jujube harvester.

\section{Jujube garden test}

In order to test the operation performance of the jujube 
harvester, the whole set of experiments was carried out in the Jujube High-Efficiency Cultivation Demonstration Garden in Company 5, 11th Regiment, Alaer, Xinjiang on October 5, 2016. The test object was 5-year-old jujube trees.

\subsection{Test conditions}

The dwarf and close planting mode in jujube gardens is illustrated in Table 3.

At the jujube harvester operating speed of $0.5 \mathrm{~m} / \mathrm{s}, 0.6 \mathrm{~m} / \mathrm{s}$ and $0.7 \mathrm{~m} / \mathrm{s}$ respectively, the calculation methods of the measured ground jujube picking rate $(g)$, tree jujube harvesting rate $(t)$ and recovery rate $(r)$ are shown as equations (9)-(11).

Table 3 Jujube dwarf and close planting mode parameters

\begin{tabular}{|c|c|c|}
\hline Name & \multicolumn{2}{|l|}{ Parameters } \\
\hline Row spacing/mm & 4000 & \\
\hline Crown diameter $/ \mathrm{mm}$ & 1000 & \\
\hline Tree height $/ \mathrm{mm}$ & 2000 & \\
\hline Trunk height/mm & $400-500$ & \\
\hline Terrain & Flat & \\
\hline$g=$ & & (9) \\
\hline$t=$ & & (10) \\
\hline$r=\frac{m_{1}}{m}$ & & (11) \\
\hline
\end{tabular}

where, $m_{1}$ is the mass of pneumatically picked jujubes in unit area, $\mathrm{kg} ; m$ is the mass of ground jujubes in unit area, $\mathrm{kg} ; m_{2}$ is the mass of jujubes harvested by vibration, $\mathrm{kg} ; M$ is the total mass of jujubes hung on the tree, $\mathrm{kg}$.

\subsection{Test results and analysis}

The test results in Table 4 showed that, the operating efficiency was low when operating speed of the jujube harvester was less than $0.5 \mathrm{~m} / \mathrm{s}$; with the speed increase of the jujube harvester $(>0.7 \mathrm{~m} / \mathrm{s})$, the picking rate of ground jujube and the harvesting rate of tree jujube were both reduced. Meanwhile, the loss rate was increased, and the damage rate changed irregularly. Therefore, when the jujube harvester operating speed was $0.5 \mathrm{~m} / \mathrm{s}$, the tree jujube picking rate, the loss rate and the damage rate all complied with the design requirements; affected by surface roughness, weeds, branches and design air ports and air speed, the ground jujube picking effect was not ideal.

Table 4 Test results

\begin{tabular}{ccccc}
\hline $\begin{array}{c}\text { Test speed } \\
/ \mathrm{m} \cdot \mathrm{s}^{-1}\end{array}$ & $\begin{array}{c}\text { Ground jujube } \\
\text { picking rate/\% }\end{array}$ & $\begin{array}{c}\text { Tree jujube } \\
\text { harvesting rate/\% }\end{array}$ & $\begin{array}{c}\text { Loss rate } \\
/ \%\end{array}$ & $\begin{array}{c}\text { Damage rate } \\
/ \%\end{array}$ \\
\hline 0.5 & 45.1 & 93.2 & 2.9 & 0.9 \\
0.6 & 37.0 & 92.1 & 3.1 & 1.2 \\
0.7 & 21.6 & 86.7 & 3.4 & 0.8 \\
\hline
\end{tabular}

\section{Summaries and conclusions}

(1) The full-hydraulic self-propelled jujube harvester is designed and is capable of completing ground jujube picking and tree jujube harvesting operation through one step;

(2) Hydraulic Model Simulation with AMESim Software, obtains the relation between the motor speed, flow and torque, and finally the hydraulic system is verified to comply with the design requirements;

(3) By means of jujube garden test result analysis of the jujube harvester, the jujube recovery rate, loss rate and damage rate meet the design requirements when the jujube harvester operating speed is $0.5 \mathrm{~m} / \mathrm{s}$.

\section{Acknowledgements}

Thanks the National Natural Science Foundation of China Based on Self-excited Vibration and Force Compensation Theory Jujube Vibration Recovery Mechanism Research (51365049), National Key Research and Development Plan - Jujube Harvesting Technical Equipment and Development (2016YFD0701504) for supporting the project, and Xinjiang Production \& Construction Corps major scientific research projects: The optimization and pilot test of self-propelled harvester of dwarf and close planting jujube (2013AA001-3).

\section{[References]}

[1] Fu W, Liu Y D, Kan Z, Pan J B, Cui J. Developing Status and Tendency of Orchard Pruning Machinery. Journal of Agricultural Mechanization Research, 2017; 10: 7-11. (in Chinese)

[2] Whitney J D. Citrus harvest results with the air shaker concept. Fla State Hort. Soc, 1972; 85: 250-254.

[3] Whitney J D, Wheaton T A. Shakers affect Florida orange fruit yields and harvesting efficiency. Applied Engineering in Agriculture, 1987; 3(1): 20-24.

[4] Hutton R J, Lill W J. Development of a mechanical harvesting system for citrus fruit. Proceedings of the International Society of Citriculture, 1982; pp.281-285.

[5] Hedden S L, Churchill D B, Whitney J D. Trunk shakers for citrus harvesting, part II: tree growth, fruit yield and removal: Applied Engineering in Agriculture, 1988; 4(2): 102-106.

[6] Blanco-Roldán G L, Gil-Ribes J A, Kouraba K, Castro-García S. Effects of trunk shaker duration and repetitions on removal efficiency for the harvesting of oil olives. Applied Engineering in Agriculture, 2009; 25(3): 329-334.

[7] Sumner H R, Coppock G E, Churchill D B, Hedden S L. Shaker removal methods affect 'Valencia' orange yield. Proceedings of the Florida State Horticultural Society, 1979; pp.54-56.

[8] Coppock G E, Grows A F, More M S. Harvesting 'Valencia' oranges with a limb shaker. Proceedings of the Florida State Horticultural Society, 1971; 11: 84-88.

[9] Mann D D, Petkau D S, Crowe T G, Schroeder W R. Removal of sea buckthorn (Hippophae rhamnoides L.) berries by shaking. Canadian Biosystems Engineering, 2002; 43(2): 23-28.

[10] Peterson D L. Mechanical harvester for process oranges. Applied Engineering in Agriculture, 1998; 14(5): 455-458.

[11] Peterson D L, Taketa F. Feasibility of mechanically harvesting fresh market quality eastern thorn less blackberry. Applied Engineering in Agriculture, 2003; 19(1): 25-30.

[12] So J D, Choi S H. Mechanical rubus coreanus miquel harvester. American Society of Agricultural and Biological Engineers, 2008; 2: 1127-1141.

[13] So J D, Cho J W. Design considerations and feasibility of a prototype mechanical bokbunja (Rubus coreanus Miquel) harvester. American Society of Agricultural and Biological Engineers, 2010; 3: 2567-2584.

[14] Lee S W, Huh Y K, So J D. Mechanical jujube (zizyphus jujube miller) harvester. CSAE/SCGR 2003 Meeting Montréal, 2003, Nov. 6-9.

[15] Tang Z H, Shen C J, Meng X J, Jia S X, Zhou Y, Zheng X. Development of 4YS-24 jujube harvester. Xinjiang Agricultural Mechanization, 2010; 1: 30-32. (in Chinese)

[16] Shi G K, Ma S H. Design and test of air suction jujube harvester. Journal of Agricultural Mechanization Research, 2014; 2: 25-53. (in Chinese)

[17] Zoltán Láng. Dynamic modelling structure of a fruit tree for inertial shaker system design. Biosystems Engineering, 2006; 93(1): 35-44.

[18] Hu R, Huang B, Li S. Simulation analysis about swing system of concrete pump based on AMESim. Machine Tool \& Hydraulics, 2015; 43(9): 169-172. (in Chinese)

[19] Zeng X F. Characteristic analysis and control strategy of hydraulic drive system of Y32-315T forging press. Central South University, 2012. (in Chinese)

[20] Wang Y, Hu J W, Luan Z Y, Zhou D R. Fault Diagnosis of a Certain Type Equipment Pitch Channel Based on AMESim Hydraulic Simulation and Test Platform. Hydraulics Pneumatics \& Seals, 2016; 12: 42-45. (in Chinese)

[21] Li J L, Hu Z Y, Guo Y K. Simulation Research of Flow Divider-combiner Based on AMESim. Mechanical Engineer, 2017; 8: 63-64. (in Chinese) 